\title{
ALTERAÇÕES ANATÔMICAS EM PLANTAS DE ALGODOEIRO COM SINTOMAS DE MURCHAMENTO AVERMELHADO $\left({ }^{1}\right)$
}

\author{
RACHEL BENETTI QUEIROZ-VOLTAN $\left(^{2}\right)$
}

\begin{abstract}
RESUMO
Estudaram-se as alteraçōes anatômicas em plantas de algodoeiro com sintomas de murchamento avermelhado em dezembro de 1993-fevereiro de 94. Analisaram-se amostras de raiz, caule e folha de Gossypium hirsutum L. 'IAC 20'provenientes de áreas de ocorrência do sintoma. Estimou-se o número de glândulas secretoras das folhas dos cultivares IAC 20 e CNPA ITA 90 (que se tem mostrado resistente). Observou-se que as células parenquimáticas apresentavam, no interior, substâncias insolúveis em água, cuja concentração aumentava à medida do grau do sintoma. As folhas apresentaram uma concentração maior dessas substâncias em relação ao restante do corpo vegetal. Os núcleos das células do parênquima paliçádico encontravam-se aumentados e os cloroplastos do mesofilo, parcialmente destruídos. As plantas com alto grau de sintoma apresentavam também um número maior de glândulas secretoras nas folhas.
\end{abstract}

Termos de indexação: algodoeiro, Gossypium hirsutum L., murchamento avermelhado, anatomia.

\section{ABSTRACT \\ ANATOMICAL ALTERATIONS IN COTTON PLANTS WITH REDDISH WITHERING SYMPTOMS}

Anatomical alterations in cotton plants (Gossypium hirsutum L.) with reddish withering symptons observated between December/93 to February/94 were studied. Samples of root, stem and leaf of Gossypium hirsutum L. 'IAC 20' collected in several sites with symptoms occurrence were analised. The number of secretory glands in the leaves of cultivar IAC 20 , and for the resistent cultivar CNPA ITA 90 was cstimated. The parenchyma cells included insoluble substances, and these concentrations increased with the crescent symptoms. The leaves presented higher concentration of these substances than the remaining plant body. The nucleus of palisade parenchyma cells was increased and the chloroplasts partially destroyed. The leave secretory glands number increases proportionally to the advance of the symptoms.

Index terms: cotton plants, Gossypium hirsutum L., reddish withering, anatomy.

( $\left.{ }^{1}\right)$ Recebido para publicação em 11 de outubro de 1994 e aceito em 23 de fevereiro de 1995.

(2) Seção de Botânica Econômica, Instituto Agronômico (IAC), Caixa Postal 28, 13001-970 Campinas (SP). 


\section{INTRODUÇÃO}

Observou-se em dezembro de 1993-fevereiro de 94 , em cultura de algodoeiro, que suas folhas amareleciam e, posteriormente, tornavam-se avermeIhadas, até que murchavam, causando a morte de algumas plantas. Tal sintoma foi chamado, impropriamente, vermelhão e bronzeamento, termos descritos para outros tipos de sintomas (Costa \& Sauer, 1954); no Instituto Agronômico de Campinas, passou-se a designá-lo murchamento avermelhado do algodoeiro.

A distribuição do sintoma ocorreu não só em toda a extensão da área cultivada como, também, em plantas isoladas e em trechos de 1 a $2 \mathrm{~m}$ na linha de plantio, em variados tipos de solo, com diferentes tipos de adubação, em solos cultivados por diversos anos e também em áreas no primeiro ano de cultivo - solo em equilíbrio biológico. Além disso, as variações climáticas foram coincidentes ou não, nas diferentes áreas.

Este trabalho objetivou verificar, mediante estudo anatômico de plantas de algodoeiro, a ocorrência de alguma alteração morfológica que pudesse auxiliar na elucidação desse sintoma.

A anatomia de Gossypium hirsutum L. foi estudada por Hayward (1938) e Webber (1938), havendo também estudos de anatomia patológica de algodoeiro (Dharmarajulu, 1932) e outros mais relacionados com as glândulas secretoras lisígenas dessas plantas e sua interação com insetos (Stanford \& Viehoever, 1918; Bottger et al., 1964, e Jenkins et al., 1966).

\section{MATERIAL E MÉTODOS}

As amostras de Gossypium hirsutum L. 'IAC $20^{\prime}$ utilizadas para a realização deste trabalho foram coletadas na Fazenda Alvorada, Goiatuba (GO); na Estação Experimental de Votuporanga, IAC (SP); na Fazenda Americaninha, Leme (SP) e no Centro Experimental de Campinas, IAC (SP). As do cultivar CNPA ITA 90 foram coletadas no Centro Experimental de Campinas.

Segmentos pequenos de raízes, caules, pecíolos e limbo de folhas adultas, provenientes de plantas sadias e das portadoras do sintoma de murchamento avermelhado, foram fixados em F.A.A. 50 (Johansen, 1940), desidratados em séric alcoólico-etílica, incluídos em parafina e cortados em micrótomo rotativo, com $12 \mu \mathrm{m}$ de espessura. Os cortes transversais e longitudinais foram corados com safranina - "alcian blue" (Gabrielli, 1992). Os segmentos do limbo foram retirados na região da nervura principal, na porção mediana da lâmina; os do pecíolo, na porção mediana; os do caule, na altura do $4 .^{\circ}$ ou $5 .^{\circ}$ nó; e os das raízes, a $3 \mathrm{~cm}$ do ápice das raízes laterais.

Para verificar se havia alguma relação entre a estrutura anatômica e os graus de sintoma, estudaram-se as raízes, caules e folhas do material procedente de Leme, separado nas seguintes categorias: (a) plantas aparentemente sadias - valor de sintoma 1; (b) plantas com graus intermediários de sintoma - valores 2 e 3 ; (c) plantas em fase de murchamento, mas não senescentes - valor de sintoma 4 .

Nas folhas provenientes de plantas com diferentes valores de sintoma e naquelas obtidas a partir do cultivar CNPA ITA 90, que se tem apresentado resistente ao sintoma, avaliou-se o número de glândulas por centímetro quadrado, com o propósito de averiguar a possibilidade de relação entre a presença dessas glândulas secretoras e o sintoma de murchamento avermelhado. Os dados foram analisados estatisticamente ao nível de $5 \%$.

Depositaram-se o material fixado e as lâminas preparadas na coleção de lâminas do Laboratório de Anatomia Vegetal da Seção de Botânica Econômica do Instituto Agronômico (SP).

\section{RESULTADOS E DISCUSSÃO}

As raízes primárias do algodoeiro possuem um parênquima cortical limitado externamente pela epiderme e, internamente, pela endoderme. No córtex, ocorrem também glândulas secretoras lisígenas. Abaixo da endoderme, tem-se o periciclo, que envolve os feixes vasculares, sendo o xilema, geralmente do tipo protostelo tetrarco, alterno com o floema. O câmbio vascular entra em atividade e dá início ao crescimento secundário (Figura 1A), originando o xilema e o floema secundários. $\mathrm{O}$ pa- 
O caule de uma planta sadia de algodoeiro, em estrutura primária, apresenta vários feixes vasculares separados por tecido parenquimático. A medula consiste em células parenquimatosas com pequenos espaços entre elas. Com o crescimento secundário (Figura 2 A e B), diferenciam-se o floema e o xilema secundários. Com o amadurecimento da estrutura primária, há maior diferenciação do colênquima na região mais externa do córtex. Neste, encontram-se muitas glândulas secretoras. Revestindo-o, ocorre uma única camada de epiderme, que pode ser substituída mais tarde pela periderme. O floema secundário apresenta grande número de fibras com paredes espessadas, enquanto o xilema secundário não se revela fortemente lig- nificado. Nas células parenquimáticas dos tecidos vasculares, ocorrem drusas (oxalato de cálcio) (Figura 2 B, DR). O pecíolo assemelha-se à descrição efetuada para o caule (Figura 3 A e B).

O caule (Figura $2 \mathbf{C}$ e $\mathbf{D}$, setas) e o pecíolo (Figura $3 \mathbf{C}$ e $\mathbf{D}$, setas) de plantas com sintoma apresentam as mesmas substâncias observadas na raiz; ocorrem no interior de células epidérmicas e células parenquimáticas do córtex, tecidos vasculares e medula (setas), sendo mais freqüentes nos pecíolos do que nos caules e raízes. Nos cortes longitudinais de caules e pecíolos, podem-se observar cordões de células com essas características ao longo do eixo (Figura 2 D e 3 D).
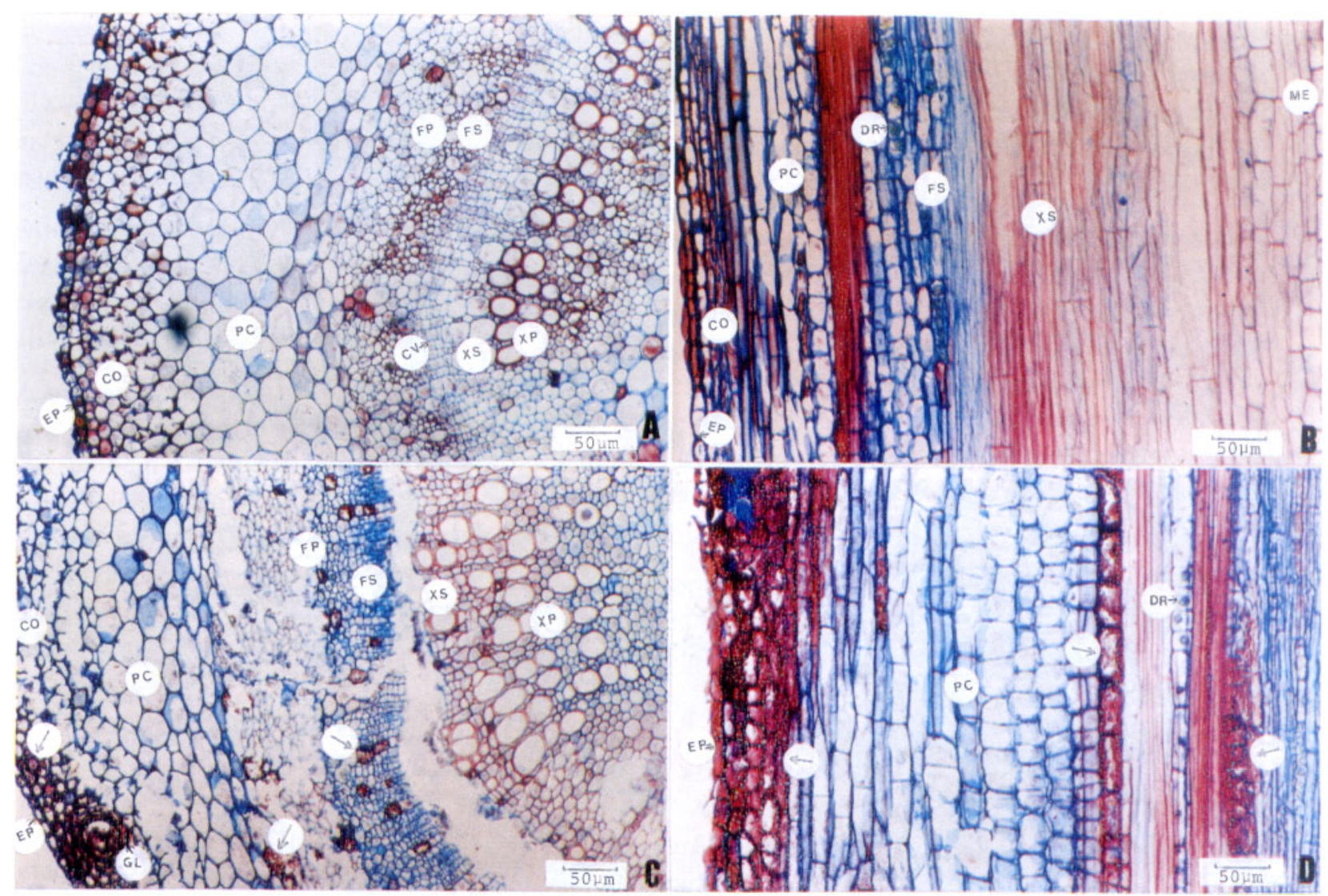

Figura 2. Caules de Gossypium hirsutum L. 'IAC 20' em estrutura secundária na região do quarto nó. A e B: Corte transversal e longitudinal, respectivamente, de plantas sem sintoma; C e D: Corte transversal e longitudinal, respectivamente, de plantas com sintoma de murchamento avermelhado. EP: epiderme; CO: colênquima; PC: parênquima cortical; CV: câmbio vascular; DR: drusa; FP: floema primário; FS: floema secundário; GL: glândula secretora; XP: xilema primário; XS: xilema secundário; ME: medula. As setas indicam a presença de substâncias no interior de células parenquimáticas. 
As folhas de algodoeiro são dorsiventrais. Os estômatos, presentes nas duas epidermes, mostram-se mais numerosos na face abaxial. As glândulas secretoras lisígenas localizam-se no parênquima lacunoso. Na região das nervuras, as células abaixo da epiderme são colenquimatosas e, envolvendo o feixe vascular, ocorre um tecido parenquimatoso. Os feixes vasculares são colaterais, semelhantes ao arranjo encontrado no pecíolo. Encontram-se nectários extraflorais na superfície abaxial da nervura principal das folhas.

Constatou-se, na região das nervuras das folhas de plantas com sintoma de murchamento avermelhado, uma distribuição semelhante à que ocorre no pecíolo. Ao longo do limbo (Figura 4 B), essas substâncias ocorrem na epiderme e, freqüentemente, no mesofilo. Constatou-se, ainda, que os núcleos das células do parênquima paliçádico se apresentam aumentados (setas) e os cloroplastos do mesofilo, em grande parte, destruídos. Daí a dificuldade para a obtenção de bons cortes do limbo foliar.

Nas amostras procedentes de Leme com os diferentes valores de sintoma, detectou-se que nas plantas com valor 1 , aparentemente sadias, a estrutura anatômica é semelhante à descrita por autores como Hayward (1938) e Webber (1938); naquelas com valores de sintoma crescente 2,3 e 4 , a quantidade de células epidérmicas e parenquimáticas, contendo substâncias insolúveis em água, aumenta à proporção do sintoma. As folhas das plantas com valor 4 mostram quase todo o conteúdo celular do mesofilo preenchido por essas substâncias, além da destruição dos seus cloroplastos.
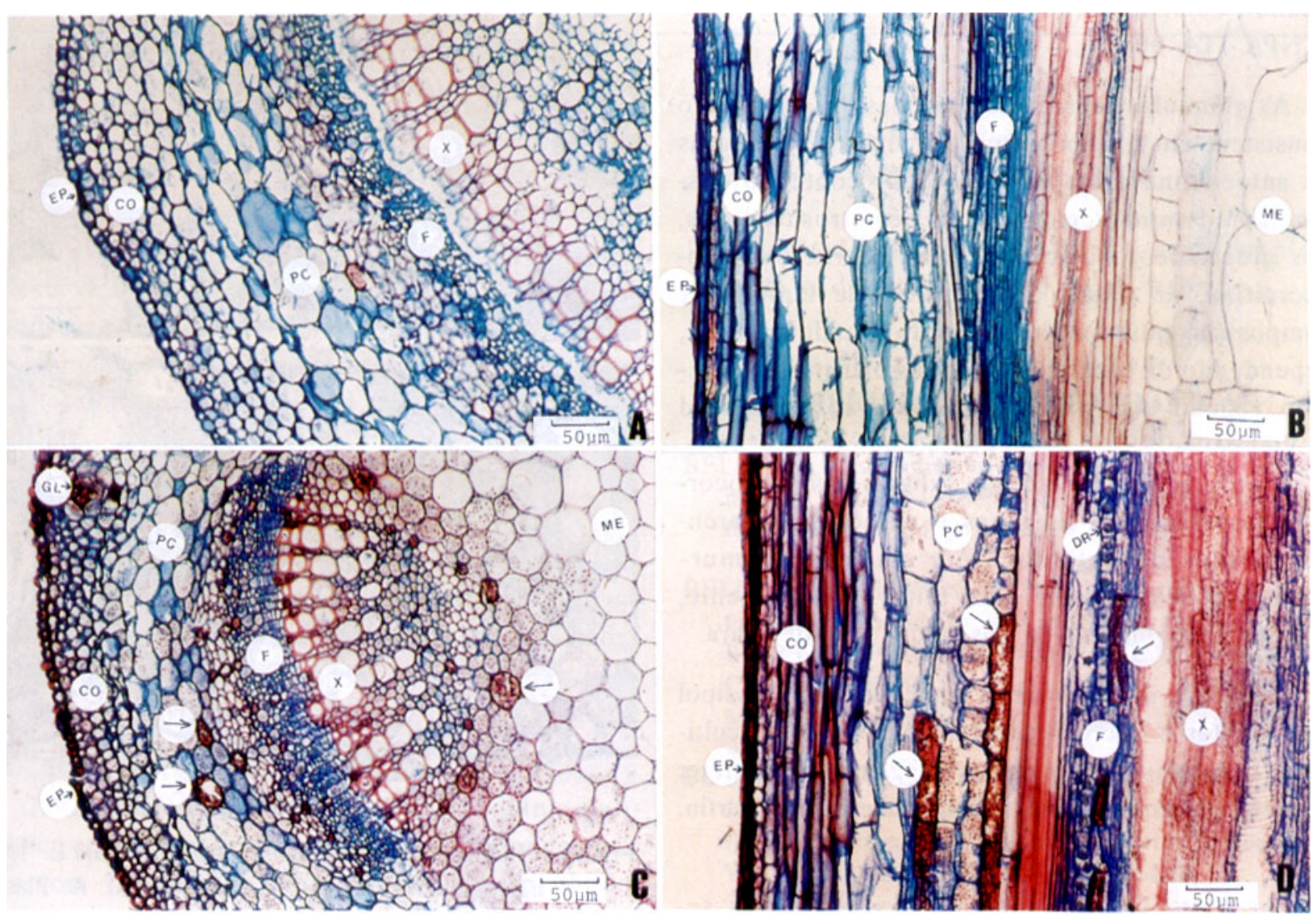

Figura 3. Pecíolos de Gossypium hirsutum L. 'IAC 20 ' em estrutura primária na região mediana. A e B: Corte transversal e longitudinal, respectivamente, de plantas sem sintoma; C e D: Corte transversal e longitudinal, respectivamente, de plantas com sintoma de murchamento avermelhado. EP: epiderme; CO: colênquima; PC: parênquima cortical; DR: drusa; F: floema; GL: glândula secretora; X: xilema; ME: medula. As setas indicam a presença de substâncias no interior de células parenquimáticas. 
As plantas com sintoma apresentam um número maior de glândulas secretoras, quando comparadas àquelas sem sintoma; além disso, as observaçôes de campo demonstraram que plantas com sintoma de murchamento avermelhado hospedam um número maior de afídeos do que as sem sintoma, e que o cultivar CNPA ITA 90 não apresenta os sintomas de murchamento avermelhado. Do quadro l pode-se depreender, através dos intervalos de confiança, que em plantas do 'IAC $20^{\prime} \mathrm{com}$ valor 4 ocorre um número significativamente maior de glândulas secretoras, enquanto nas plantas de valores de sintoma 1, 2 e 3, cujos intervalos de confiança se sobrepõem, não existem diferenças no número glandular. No 'CNPA ITA 90', o número médio de glândulas por centímetro quadrado é semelhante ao do 'IAC $20^{\prime}$ de valor 1 . O coeficiente de variação dos valores intermediários 2 e 3 mostrou-se alto, quando comparado ao 1 e ao 4 do 'IAC 20' e do 'CNPA ITA 90'.

As glândulas secretoras lisígenas do algodoeiro consistem em um envclope de células portadoras de antocianina e em uma cavidade contendo gossipol, predominantemente, além de outros terpenos, dos glucosídeos quercitina, quercimeritrina e isoquercitina, de óleos, de resinas e de taninos. A composição química do conteúdo glandular varia, dependendo da localização dessas estruturas no tecido vegetal e de sua exposição à luz (Stanford \& Viehoever, 1918; Bell, 1967; Chan et al., 1983). A identificação química das substâncias que ocorrem nas glândulas lisígenas e nas células parenquimáticas das plantas com sintoma de murchamento avermelhado será feita oportunamente, visando correlacioná-la aos dados de literatura.

Trabalhos demonstram a toxicidade do gossipol para insetos e microorganismos, que preferem cultivares com um número menor de glândulas (Bottger et al.,1964; Jenkins et al., 1966; Lukefahr \& Martin, 1966).

Por outro lado, o conteúdo das glândulas secretoras não deve ser repelente ou tóxico para todos os insetos, pois os afídeos perfuram as glândulas e sugam parte dessas substâncias. É provável que as substâncias sugadas consistam em açúcar (dextrose), que se pode formar a partir da hidrólise de glucosídeos (Stanford \& Viehoever, 1918). Talvez isso explique a maior presença desses afídeos nas plantas com valor 4, que possuem um número significativamente maior dessas glândulas.

Sabe-se que o gossipol se forma em todos os tecidos do algodoeiro em resposta a agentes irritantes como patógenos, inibidores metabólicos e sais de metais pesados, e que tais irritantes eventualmente causam necrose nos tecidos afetados. A síntese do gossipol restringe-se a células ou tecidos vivos irritados, e sua indução depende do genótipo, da quantidade e da qualidade do irritante e da condição fisiológica dos tecidos (Bell, 1967; Bell \& Stipanovic, 1977).

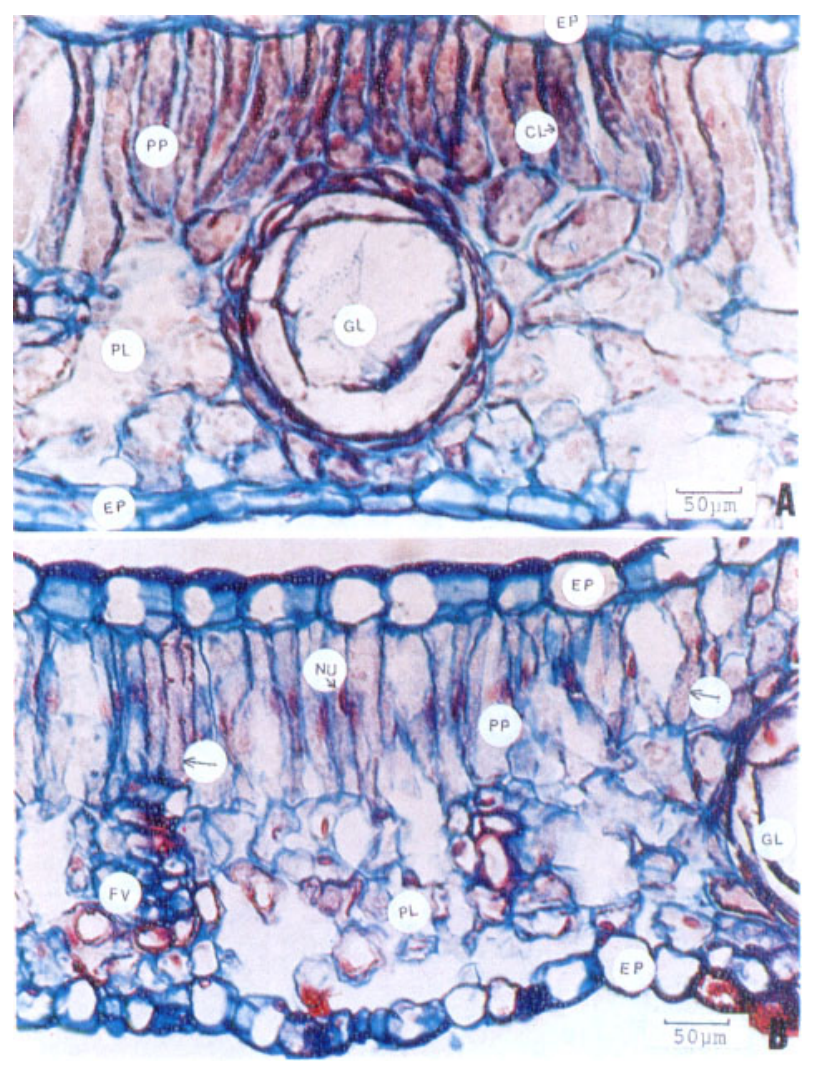

Figura 4. Folhas maduras de Gossypium hirsutum L. 'IAC $20^{\prime}$ na região mediana. Corte transversal. A: Planta sem sintoma. B: Planta com sintoma de murchamento avermelhado. CL: cloroplasto; EP: epiderme; GL: glândula secretora; FV: feixe vascular; PP: parênquima paliçádico; PL: parênquima lacunoso; NU: núcleo. As setas indicam a presença de substâncias no interior de células parenquimáticas. 
Quadro 1. Média $(\bar{x})$, desvio-padrão (S), coeficiente de variação (CV) e intervalo de confiança (IC) do número de glândulas secretoras lisígenas por centímetro quadrado de algodoeiros 'IAC 20' e 'CNPA ITA 90' em diferentes intensidades de sintomas de murchamento avermelhado $(n=30)$
Cultivares
$\overline{\mathrm{x}}$
$\mathrm{S}$
CV
IC

\begin{tabular}{|c|c|c|c|c|}
\hline Sintoma 1 (Sadio) & 72,19 & 12,00 & 16,63 & $(67,79 ; 76,59)$ \\
\hline IAC 20 & & & & \\
\hline Sintoma 2 & 81,58 & 24,68 & 30,26 & $(72,53 ; 90,63)$ \\
\hline $\begin{array}{l}\text { IAC } 20 \\
\text { Sintoma } 3\end{array}$ & 71,23 & 19,41 & 27,25 & $(64,11 ; 78,34)$ \\
\hline IAC 20 & & & & \\
\hline Sintoma 4 & 113,86 & 19,02 & 16,71 & $(106,89 ; 120,83)$ \\
\hline CNPA ITA 90 & 65,09 & 9,29 & 14,27 & $(61,68 ; 68,50)$ \\
\hline
\end{tabular}

Da mesma forma, sabe-se que os afídeos são vetores de algumas raças de vírus que causam doenças no algodoeiro, como, por exemplo, o vermelhão (Costa \& Sauer, 1954); portanto, estudos aprofundados de interação desses organismos com plantas de algodoeiro de cultivares sensíveis ou resistentes ao murchamento avermelhado, merecem ser iniciados.

\section{CONCLUSÕES}

1. Plantas com sintomas de murchamento avermelhado apresentam substâncias no interior das células epidérmicas (em menor proporção) e parenquimáticas, distribuídas por todo o corpo vegetal, com maior concentração nas folhas.

2. Os núcleos das células do parênquima paliçádico encontram-se aumentados nas folhas de plantas com sintoma de murchamento avermelhado, estando os cloroplastos do mesofilo, em grande parte, destruídos.

3. As folhas de plantas com sintoma apresentam um número maior de glândulas secretoras lisígenas em relação às plantas sadias.

\section{AGRADECIMENTOS}

À Seção de Algodão, pelo fornecimento das plantas para o desenvolvimento deste trabalho.

\section{REFERÊNCIAS BIBLIOGRÁFICAS}

BELL, A.A. Formation of gossypol in infected or chemically irritated tissues of Gossypium species. Phytopathology, St. Paul, 57:759-764, 1967.

BELL, A.A. \& STIPANOVIC, R.D. Variation of structures of terpenoids in wild species of Gossypium. In: BELTWIDE COTTON PRODUCTION RESEARCH CONFERENCES, Atlanta, 1977. Proceedings. Menphis, National Cotton Council, 1978. p.51.

BOTTGER, G. T.; SHEEHAN, E. T. \& LUKEFAHR, M. J. Relation of gossypol content of cotton plants to insect resistance. Journal Economic Entomology, Washington, D.C., 57:283-285, 1964.

CHAN, B.G.; MAHONEY, N. \& WAISS JR., A.C. A quantitative method for gossypol and its analogs. In: BELTWIDE COTTON PRODUCTION RESEARCH CONFERENCES, San Antonio, 1983. Proceedings. Memphis National Cotton Council of America, 1983. p.64-65. 
COSTA, A.S. \& SAUER, H. F. G. Vermelhão do algodoeiro. Bragantia, Campinas, 13:237-246, 1954.

DHARMARAJULU, K. A study of the pathological anatomy of the cotton plant in connection with the wilt disease. Indian Journal of Agricultural Sciences, New Delhi, 2(3):293-313, 1932.

GABRIELLI, A. C. Contribuição ao estudo anatômico da raiz de Pyrostegia venusta (ker) Miers-Bignoniaceae. Revista Brasileira de Botânica, São Paulo, 15(2):95-104, 1992.

HAYWARD, H. E. The structure of economic plants. New York, The Macmillan Company, 1938. 674 p.

JENKINS, J. N.; MAXWELL, F. G. \& LAFEVER, H. $\mathrm{N}$. The comparative preference of insects for glanded and glandless cottons. Journal Economic Entomology, Washington, D.C., 59:352-356, 1966.
JOHANSEN, D.A. Plant microtechnique. New York, McGraw-Hill, 1940. 523p.

LUKEFAHR, M. D. \& MARTIN, D. F. Cotton-plant pigments as a source of resistance to the bollworm and tobacco budworm. Journal Economic Entomology, Washington, D.C., 59:176-179, 1966.

STANFORD, E. E. \& VIEHOEVER, A. Chemistry and histology of the glands of the cotton plant, with notes on the occurrence of similar glands in related plants. Journal of Agricultural Research, Washington, D.C., 13(8):419-435, 1918 .

WEBBER, I. E. Anatomy of the leaf and stem of Gossypium. Journal of Agricultural Research, Washington D.C., 57(4):269-286, 1938. 